\title{
PROGRAMAS SOCIAIS VISTOS COMO UM AUXÍLIO NA PROMOÇÃO DO DESENVOLVIMENTO LOCAL: UM PROGNÓSTICO SOBRE A IMPLEMENTAÇÃO DO PROGRAMA PASSE LIVRE UNIVERSITÁRIO NO MUNICÍPIO DE ITAOCARA (RJ)
}

\author{
SOCIAL PROGRAMS REGARDED AS SUPPORT TO PROMOTE LOCAL DEVELOPMENT: A \\ PROGNOSIS ON THE IMPLEMENTATION OF THE UNIVERSITY FREE PASS PROGRAM IN \\ THE MUNICIPALITY OF ITAOCARA, RIO DE JANEIRO STATE, BRAZIL
}

Resumo: 0 presente trabalho tem por objetivo verificar a possibilidade de o programa Passe Livre Universitário ser destinado não só para além de uma política de acesso ao ensino superior, mas também para uma política que possibilita o estímulo sobre o desenvolvimento local no município de Itaocara (RJ). Para este estudo, utiliza-se como crítica o Modelo da Tríplice Hélice, o qual defende o conhecimento como transformador e provedor de desenvolvimento regional/ local. Neste estudo, o governo foi identificado como um elo necessário entre a tríplice governo-universidade-empresa para impulsionar mudanças locais em cidades pequenas. Foi, então, realizado um breve estudo de caso no município de Itaocara, situado na Mesorregião Noroeste Fluminense, apontando a percepção dos entrevistados - atores envolvidos na execução do programa - sobre suas intervenções realizadas através da implementação de programas sociais - especificadamente o programa Passe Livre Universitário - e seus possíveis efeitos sobre a população.

Palavras-Chave: Passe Livre Universitário. Transporte Universitário. Desenvolvimento Local. Políticas Sociais. Tríplice Hélice.
Abstract: This work aims at verifying the possibility of the University Free Pass program being destined not only for a policy of access to higher education, but also for a policy that stimulates local development in the municipality of Itaocara, Rio de Janeiro State, Brazil. This study is based on the Triple Helix Model, which supports the idea of knowledge as a transforming factor and provider of regional/ local development. Within this study, the government was identified as a needed connection between the threefold government-university-company to foster local change in small towns. A brief case study was then conducted in the municipality of Itaocara, located in the Northwestern region of Rio de Janeiro State, Brazil, showing the perception of the interviewees - actors who played a role in the implementation of the program - about their interventions by implementing social programs - specifically the University Free Pass program - and their possible effects on the population

Keywords: University Free Pass. University Transportation. Local Development. Social Policies. Triple Helix.

\section{Laira Thamys de Araujo Silva}

Bacharel em Administração Pública pela Universidade Estadual do Norte Fluminense Darcy Ribeiro - UENF. Mestranda em Políticas Sociais pela Universidade Estadual do Norte Fluminense Darcy Ribeiro - UENF. lairathamys@hotmail.com

\section{Joseane de Souza}

Professora associada da Universidade Estadual do Norte Fluminense Darcy Ribeiro - UENF, Centro de Ciências do Homem, Laboratório de Gestão e Políticas Públicas - LGPP.

joseanedesouza.souza@gmail.com
Edson Terra Azevedo Filho

Professor Associado da Universidade Estadual do Norte Fluminense Darcy Ribeiro - UENF do Laboratório de Engenharia de Produção - LEPROD. edsonterrafilho@gmail.com 


\section{Introdução}

0 desenvolvimento social é um assunto bastante explorado para trabalhar aspectos regionais, em determinado tempo e espaço. Existem algumas variações nas abordagens, de acordo com os autores trabalhados, na teoria desenvolvida por Etzkowitz, conhecida como modelo Tríplice Hélice, as interações promovidas através do elo indústria-universidade-governo "são a chave para o crescimento econômico e o desenvolvimento social baseados no conhecimento" (ETZKOWITZ e ZHOU, 2017, p. 24). A interação entre estas três instituições é fator determinante para gerar desenvolvimento e inovação em uma sociedade/localidade. Em linhas gerais, pelo menos uma dessas organizações deve tomar ações que, segundo os autores, impulsionem as ações dos demais atores, ou seja, das demais "hélices", para gerar ou alterar resultados necessários.

Se considerarmos uma nação desenvolvida, onde os três elos funcionam de forma integrada e constante, é relativamente fácil imaginar e acreditar nos resultados positivos da interação entre a indústria, as universidades e o governo para a sociedade como um todo. Porém, em países em desenvolvimento, nem sempre essa teoria consegue ser visualizada com a mesma dimensão, por conta das falhas existentes em algumas dessas organizações. Se trouxermos para o campo empírico, é mais fácil enxergarmos tal realidade nos municípios com baixo poder econômico, afastados das grandes metrópoles, onde normalmente há poucas indústrias - às vezes nenhuma - e também poucos centros de pesquisa e desenvolvimento tecnológico. Segundo um estudo realizado por Santos $(2004$, p. 9) sobre o estado do Rio de Janeiro, "as cidades com os maiores índices de pobreza se encontram, principalmente, nas Regiões Norte e Noroeste do estado, caracterizando um inibido desenvolvimento em relação aos outros municípios."

É necessário considerar o fato de que os municípios do estado do Rio de Janeiro possuem disparidades relativamente grandes entre eles no quesito concentração de renda. Uma região rica não necessariamente é uma região desenvolvida se grande parcela da população não tem acesso aos bens e serviços. Portanto, para que essas disparidades sociais sejam solucionadas, é necessário que autoridades locais tomem providências. De acordo com a teoria da Tríplice Hélice, o papel do governo

[...] deve ser moderador, não controlador. Seu objetivo é garantir que a Hélice Tríplice funcione bem, incluindo as hélices duplas governo-universidade, universidade-indústria e indústria-governo, assim como as três hélices simples. 0 governo pode ser o melhor candidato para criar um "espaço de consenso" reunindo os protagonistas relevantes para conceber e implementar projetos de inovação. (ETZKOWITZ; ZHOU, 2017, p. 33).
Nesse sentido, o Estado possui posição e ferramentas importantes para a manutenção do equilíbrio entre os três elos, além do importante papel político que possui de manter a harmonia entre os vários atores sociais, para possibilitar a transformação local através do desenvolvimento, de forma integrada e eficaz. Nos municípios do Norte eNoroesteFluminense, os governos municipais têm desenvolvido, ao longo das últimas décadas, algumas ações de políticas públicas para promover mudanças sociais. No setor da educação, por exemplo, podemos mencionar os programas que têm possibilitado o acesso dos estudantes às instituições de ensino superior em municípios próximos, através da concessão de transportes públicos.

Neste estudo, apresentaremos o caso do município de Itaocara, situado no Noroeste Fluminense. Analisaremos a implementação do programa Passe Livre Universitário como ação estatal transformadora, no que se refere ao acesso ao ensino superior e incentivo à formação profissional, sanando a falta da oferta de ensino superior público no município. Buscaremos apresentar, no decorrer do trabalho, quais são as perspectivas, na visão da prefeitura do município, sobre os resultados e os efeitos gerados ao município e à população local.

Portanto, este trabalho possui como objetivo geral investigar o programa Passe Livre Universitário não apenas como uma política de acesso ao ensino superior, mas também como uma política que possibilite caminhos para o desenvolvimento local no município de Itaocara (RJ). Nesse sentido, o artigo está organizado em quatro seções, além desta primeira, que é introdutória. Na segunda seção, apresentaremos uma breve revisão bibliográfica sobre a importância da política social para a sociedade e alguns desdobramentos relevantes. Como se trata de um estudo de caso, na terceira seção, discorreremos brevemente sobre o município de Itaocara (RJ) para apresentar algumas de suas características socioeconômicas. Na quarta seção, analisaremos o programa Passe Livre Universitário, identificando como essa política tem sido aplicada no município; quais foram os critérios utilizados pelo poder público para sua elaboração; o processo de implementação; os critérios de elegibilidade; e se há perspectivas do município ofertante quanto a efeitos locais (econômico, social, educacional) ao implementar o programa. Na quinta e última seção, apresentaremos as principais conclusões da pesquisa. 


\section{Política social como ação transformadora nos municípios pequenos}

Em um país tão diverso como o Brasil, considerando sua extensão territorial, sua história, sua cultura, é inevitável não considerar também a sua disparidade social. A desigualdade social no Brasil é um problema que tem sido confrontado por anos, refletindo em como o País tem se desenvolvido e crescido economicamente. Algumas políticas têm sido implementadas através de governos locais com o intuito de minimizar diferenças sociais encontradas em determinada sociedade. Segundo Jaccoud (2009, p. 70), "uma política de combate à pobreza e à desigualdade implica o amadurecimento de um projeto de desenvolvimento com equidade [...]", criando, portanto, oportunidades semelhantes aos cidadãos e o fortalecimento de uma sociedade. A partir desse 'nivelamento' social, seria possível apostar em um novo processo de desenvolvimento que fosse "capaz de promover o crescimento econômico, mediante elevação da produtividade econômica da força de trabalho historicamente excluída de mercados estruturados e de políticas públicas mais inclusivas." (JACCOUD, 2009, p. 71). Outros autores, como Draibe e Riesco (2011, p. 224), também defendem a aplicação de políticas sociais como agentes de mudanças sociais e regionais, afirmando a "capacidade dos sistemas de política social em promover e facilitar o crescimento econômico, simultaneamente ao desenvolvimento social". É importante ressaltar que existe uma diferença a ser considerada entre o crescimento e 0 desenvolvimento econômico, visto que a elevação do produto e o aumento da produtividade dos fatores de produção não, necessariamente, fazem com que haja melhora na qualidade de vida da população residente. Pelo contrário, o crescimento econômico concentrado nas mãos de determinado grupo eleva a desigualdade social. "A distribuição dos frutos do progresso técnico é tão importante quanto o aumento da riqueza. A distribuição mais equitativa da riqueza revela que o desenvolvimento é um estágio superior ao simples crescimento econômico" (OLIVEIRA; QUINTAIROS, 2011, p. 263 apud ALMEIDA, SILVA; OLIVEIRA, 2014, p. 335).

No entanto, nem todas as políticas sociais atuam diretamente na eliminação da pobreza, mas proporcionam outros tipos de igualdade social, como é o caso das políticas de acesso à educação. No artigo 211 da Constituição Federal de 1988, encontram-se as competências destinadas a cada ente federado e as suas responsabilidades sobre os níveis de escolaridade, conforme apresentado:

Art. 211. A União, os Estados, o Distrito Federal e os Municípios organizarão em regime de colaboração seus sistemas de ensino.

$\S 1^{\circ} \mathrm{A}$ União organizará o sistema federal de ensino e o dos Territórios, financiará as instituições de ensino públicas federais e exercerá, em matéria educacional, função redistributiva e supletiva, de forma a garantir equalização de oportunidades educacionais e padrão mínimo de qualidade do ensino mediante assistência técnica e financeira aos Estados, ao Distrito Federal e aos Municípios.

$\S 2^{\circ}$ Os Municípios atuarão prioritariamente no ensino fundamental e na educação infantil.

$\S 3^{\circ}$ Os Estados e o Distrito Federal atuarão prioritariamente no ensino fundamental e médio. (BRASIL, 1990)

Embora, em relação à educação, ocorra a distribuição dos deveres do Estado entre os entes federados, é preciso atentar para o fato de que as oportunidades de acesso ao ensino não são, por diversos fatores, igualmente ofertadas à população. Dentre os fatores que limitam as oportunidades do acesso, destacam-se: a necessidade econômica, que leva muitos indivíduos a optarem pelo trabalho e a abandonarem os estudos; a distância territorial entre o local de residência e o local de estudo, o que implica gastos com passagem, alimentação e, em alguns casos, hospedagem; e outras questões que envolvem a permanência e a conclusão do estudo.

Quando a educação não está ao alcance de determinada população, é necessária, então, a implementação de políticas públicas que a direcionem a esse acesso. Essa situação - de pouca oportunidade de acesso ao ensinotem se destacado atualmente, principalmente no que se refere ao acesso ao ensino superior. Alguns municípios, principalmente os localizados longe das metrópoles ou dos polos regionais, embora possuam demanda por educação superior, muitas vezes não contam com Instituição Superior de Ensino (IES) em seus territórios. Este é o caso de alguns municípios do Norte e Noroeste Fluminense, dentre os quais destacamos o município de Itaocara. Para suprir essa necessidade, em Itaocara, o poder público implementou, como se verá, o programa de transporte público universitário. 
A ausência de oportunidades de estudo e de trabalho nas cidades pequenas tende a causar a expulsão dessa população para cidades que ofereçam melhor expectativa de vida e inserção no mercado de trabalho. Quanto a esse fator, Procópio, Bastos e Fregiglia (2014, p. 610) afırmam que "a migração ocorre geralmente de regiões com menores salários e menores ofertas de emprego para regiões com melhores oportunidades no mercado de trabalho", provocando, portanto, um deslocamento populacional de pessoas que não encontram em seus municípios a perspectiva de vida que gostariam de vivenciar. Os mesmos autores complementam o raciocínio ao dizer que "regiões com mais alto nível de desenvolvimento e maiores rendas per capita atraem trabalhadores que buscam melhores oportunidades de emprego e renda" (PROCÓPIO; BASTOS; FREGIGLIA, 2014, p. 610).

Segundo Kliksberg (1997, p. 169), "um requisito essencial para a efetividade de um programa social é o de que haja possibilidade real de acesso a seus benefícios potenciais". Por isso, espera-se que, além de eficiente, um programa social deva ser eficaz. Se o programa Passe Livre Universitário em Itaocara, funcionar com o propósito de ofertar serviços de transporte público universitário para a população, além de atender à demanda local, assegurará, paralelamente, que os cidadãos permaneçam como moradores e eleitores do município, aprimorando, portanto, o nível de escolaridade da população.

\section{MES T R A D 0}

\section{PESQUISA OPERACIONAL E}

INTELIGÊNCIA COMPUTACIONAL

\section{LINHA DE PESQUISA}

\section{EM SAÚDE}

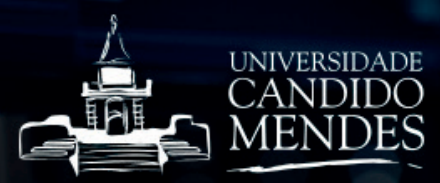




\section{Breve caracterização socioeconômica do município de Itaocara (RJ)}

O município de Itaocara está localizado no estado do Rio de Janeiro, na Mesorregião Noroeste Fluminense. De acordo com o Censo 2010, o município possui uma população de 22.899 habitantes. Atualmente, sua população encontrase em torno de 23.234 habitantes (IBGE, 2010). Sua extensão territorial é de $433.397 \mathrm{~km}^{2}$, e sua densidade demográfica é algo em torno de 53,09 habitantes/km2. Segundo o IBGE Cidades, o salário médio mensal dos trabalhadores formais [2017] é de 1,8 salários mínimos, sendo esses trabalhadores apenas 19,4\% da população.

No que diz respeito às IES no município, é possível encontrar apenas uma unidade que oferta esse tipo de ensino (até 0 ano de 2018) por meio do polo Cederj, pela modalidade de Ensino a Distância (EAD), a qual oferece, atualmente, os seguintes cursos: Administração Pública (UFF); Licenciatura em Ciências Biológicas (UENF); Licenciatura em Matemática (UFF); Licenciatura em Pedagogia (UNIRIO); e Computação (UFF). A limitação dessa oferta no município tem feito com que parte da população que deseja cursar graduação, mestrado e doutorado procure instituições localizadas em outros municípios, colocandose na posição de tomar a decisão de ir para outras cidades. Sabemos, porém, que tal propósito depende também de outros fatores, como custo de passagem, alimentação e, por vezes, hospedagem. Essas limitações financeiras, que tem dificultado o acesso e a permanência dos estudantes no ensino superior, fizeram surgir uma demanda social, que tem sido atendida por alguns governos locais por meio de programas sociais, os quais oferecem auxílio ou transporte público universitário, o que possibilita, portanto, uma transformação social e econômica para a população local mediante a implementação de políticas sociais. Essa tem sido a realidade encontrada em diversos municípios do estado do Rio de Janeiro, e muitos desses casos localizam-se nas Regiões Norte e Noroeste Fluminense.

\section{0 programa Passe Livre Universitário: para além do serviço de transporte}

Para entender como foi desenvolvida e pensada a política de passe livre universitário implementada em Itaocara, e quais os efeitos esperados para a sociedade - na percepção da Secretaria de Educação da prefeitura -, entrevistou-se um dos responsáveis pela execução do programa, o então supervisor de transportes, e foram incluídas algumas informações extras fornecidas pela secretária de Educação e outros colaboradores do setor. Para tal etapa, foi utilizado o método qualitativo, aplicando entrevistas semiestruturadas, com perguntas que nos possibilitaram compreender:
A. o contexto político em que o programa foi implementado (como e quando surgiu a proposta de implementar o programa Passe Livre Universitário no município?);
B. as características principais do programa (Comoerama proposta e os objetivos do poder público municipal com a implementação do programa? Quais os atores responsáveis pela sua implementação?); e
C. os beneficiários (Quais os critérios de elegibilidade que os demandantes deveriam atender para se tornarem beneficiários do programa?)

\section{A QUALIDADE DE ENSINO QUE VOCE JÁ CONHECE.}

INSCREVA-SE AGORA!

口 PRESENCIAL

口 SEMIPRESENCIAL

口 EAD 
Como se trata de uma pesquisa de caráter exploratório, incluíram-se no questionário alguns quesitos voltados para a obtenção de informações relativas à existência (ou não) de projetos complementares a este, uma vez que permitir o acesso à educação e, portanto, à formação profissional dos cidadãos implica, no futuro, uma demanda maior por empregos relativamente mais qualificados.

A proposta da implementação do programa no município surgiu logo após a posse do governo do Partido Socialismo e Liberdade (PSOL), mandato 20132016, com o objetivo de oferecer o benefício para estudantes que faziam cursos técnicos e superiores em outros municípios e residiam em Itaocara.

0 programa é de responsabilidade da Secretaria de Educação em conjunto com a Secretaria de Transportes, sendo os envolvidos na sua implementação. 0 foco inicial era o de atender a população que estudava em Campos dos Goytacazes ou em Itaperuna, de forma a substituir o transporte fretado e, portanto, pago com recursos próprios dos usuários, pelo transporte público, reduzindo, dessa forma, os custos para as famílias dos beneficiários. Segundo o entrevistado, para a elaboração do programa, foi realizado um 'diagnóstico' a fim de identificar a demanda pelo transporte público para os referidos municípios. Convém ressaltar que, após a implementação, o transporte público passou a incluir novos municípios de destino - São Fidélis e Santo Antônio de Pádua -, uma vez que foram identificados como destino final por uma parcela da população que se deslocava por motivo de estudo. Para Santo Antônio de Pádua, o transporte é feito com veículo próprio da prefeitura; para os demais, são utilizados transportes terceirizados, selecionados via processo licitatório. No início de 2018, foi realizada nova licitação para os transportes terceirizados, com prazo de um ano de vigência, com a promessa de que o programa continuasse funcionando até o final do mandato do governo atual (até 2020) - visto fazer parte do programa desse governo -, podendo a atual licitação ser prorrogada ou realizada outra

Em relação aos critérios de elegibilidade, não existe discriminação de quem possa usar o programa: toda pessoa que está prestando curso técnico ou universitário fora do município tem direito a utilizar o ônibus, inclusive estudantes de pré-vestibular. Os critérios para o cadastro são, basicamente, ser morador de Itaocara (comprovando residência) e possuir título de eleitor no município. 0 fato de não incluírem a comprovação de renda como critério de elegibilidade para possuir tal benefício leva a entender que (até o momento) a política é ofertada de maneira universal a todos os cidadãos itaocarenses, descartando, portanto, classificações financeiras do beneficiário.

0 cadastro é atualizado no início de cada ano letivo, ressaltando-se que a prefeitura possui um sistema com banco de dados computado, inclusive com informações pessoais dos usuários - nome do pai, da mãe, endereço, estado civil, entre outras. Foi somente a partir do atual governo que o arquivo dos usuários, antes em papel, foi transformado em arquivo digital. Segundo o entrevistado, "boa parte das informações dos antigos
A QUALIDADE DE ENSINO QUE VOGE JÁ CONHECE.
INSCREVA-SE AGORA!

口 PRESENCIAL

口 SEMIPRESENCIAL

口 EAD 
usuários foi recuperada, mas algumas informações possivelmente foram perdidas na transição do governo", uma vez que, no primeiro mandato, os cadastros eram realizados em papel impresso e, atualmente, vêm sendo realizados pelo sistema. Em decorrência disso, de acordo com o entrevistado, não há número exato de estudantes que foram beneficiados pelo programa desde sua criação até o presente momento, sendo possível apenas estimar esse quantitativo.

A princípio existia o transporte destinado aos estudantes que saíam do município no início da semana e voltavam no fim da semana, porém, com a troca de governo em 2017, essa modalidade foi cortada. Significa dizer que, atualmente, os transportes são limitados aos estudantes que vão e voltam no mesmo dia, ou seja, os que cursam o turno noturno, com foco, principalmente, nos estudantes que estudam à noite, mas trabalham durante o dia. Cabe informar que 0 transporte semanal era ofertado somente para 0 município de Campos dos Goytacazes, onde já existia demanda para essa modalidade, pois, no município, havia muitos estudantes da Universidade Estadual do Norte Fluminense Darcy Ribeiro (UENF), do Instituto Federal Fluminense Centro Campos e também do campus Guarus, onde muitos cursos são em período integral, necessitando, portanto, da presença diária e, consequentemente, semanal nos municípios onde cursavam.

Ao ser questionado, por exemplo, sobre os cursos que possuíam mais procura da população no município, foi respondido que esse tópico não era de interesse da prefeitura, embora fosse algo possível de ser analisado por meio do banco de dados, que contém as informações dos cursos matriculados e também da instituição a que pertence.

Posteriormente, foi questionado se existem projetos sendo desenvolvidos com as demais secretarias para receber demandas desses futuros profissionais que receberão seus diplomas como fruto, também, do uso do programa. Segundo o entrevistado, a prefeitura não demostra preocupação se haverá mercado de trabalho para esses futuros profissionais no município, pois sabem que a "quantidade será/está sendo superior à demanda". O que vem acontecendo é que alguns continuam no município de Itaocara, enquanto outros acabam ficando onde estudaram ou em outros municípios que possibilitam mais oportunidades no mercado de trabalho.

No que diz respeito ao posicionamento do setor privado do município de Itaocara no processo de mudança social, foi constatado que as empresas locais possuem interesse em buscar iniciativas de ofertas de emprego a partir do banco de dados, onde constam os cadastros dos usuários do programa - como um "balcão de emprego" -, para terem conhecimento sobre a oferta de profissionais do município. Também não houve essa iniciativa partindo do poder público. Algumas perspectivas mais ampliadas possibilitariam maior impacto do programa sobre outros aspectos na população. Isso faz crer que os setores econômicos, de maneira geral, têm trabalhado pouco - no sentido prático e teórico - para viabilizar um desenvolvimento local com base em modelos de desenvolvimento, como a Tríplice Hélice, mencionado no início deste trabalho.

Sobre estudos realizados para obterem conhecimento sobre o grau de escolaridade do município, renda, emprego, mercado de trabalho ou potencial econômico do município, antes da elaboração e implementação da política, foi observado que não foram feitos levantamentos de dados locais, ao menos não é sabido pelos atuais responsáveis pelo programa.

Os recursos aplicados ao programa são provenientes da arrecadação do município, sendo esses recursos - para transportes, destinados aos municípios de Itaperuna, Campos dos Goytacazes e São Fidélis - extraídos da própria Secretaria de Educação; os serviços oferecidos por terceirizados, derivados da concessão obtida pela licitação; e o transporte para o município de Santo Antônio de Pádua é concedido pela Secretaria de Transportes, veículo da própria prefeitura, embora sua supervisão também seja de responsabilidade da Secretaria de Educação. Nesse primeiro contato com os entrevistados, ainda não foi possível obter informações completas sobre os custos do programa para a prefeitura. A questão é que o Passe Livre onera o município, que não tem responsabilidade 
direta com o ensino universitário; sua responsabilidade constitucional com a educação é com a pré-escola e 0 ensino fundamental I e II. Em tempos de escassez de recursos, programas não obrigatórios tornam-se fortes candidatos a serem reduzidos (redução do escopo/abrangência), correndo o risco, inclusive, de serem extintos. É importante citar que o entrevistado não menciona o risco de extinção do programa, mas faz alusão a uma possível redução do número de beneficiários. Dessa forma, o município só pode ofertar o Passe Livre para a população se as condições financeiras permitirem a execução de tal benefício.

Em relação à implementação eà manutenção do programa, para o entrevistado 2, o poder público e a população têm percepções diferenciadas sobre o programa. 0 programa é aparentemente entendido pela própria prefeitura como um 'favor' para a população, enquanto a população tem cobrado a manutenção do funcionamento como um direito social, independentemente dos interesses políticos do governo em vigor. Interessante observar ainda que os adversários políticos do atual governo consideram 0 programa uma medida eleitoreira - troca de voto, jogo político, manutenção do curral eleitoral. Percebe-se, então, que, para a oposição, a situação financeira do município seria, por si só, uma justificativa para que o atual governo municipal extinguisse o programa. No jogo político, o governante que herdar um programa dessa natureza em um momento de crise terá uma significativa perda de capital político caso promova sua extinção.

Durante a entrevista, foram feitas algumas especulações sobre possibilidades de modificações devido à intenção do Ministério Público de, segundo os entrevistados, passar a responsabilidade do programa para a Assistência Social - tornando, assim, beneficiados apenas os estudantes de baixa renda - possivelmente utilizando informações contidas no Cadastro Único (plataforma unificada que serve como porta de entrada para vários Programas Sociais do Governo Federal) e também por meio do SISU/ENEM, o que implicaria no perfil dos usuários contemplados no todo. É evidente que a alteração do procedimento do programa, dentro dessa perspectiva, tornaria a política menos acessível a todos se comparado à maneira como é ofertada hoje. Porém, segundo o entrevistado, no momento, essas informações são apenas discussões, visto que o Ministério Público não formalizou tal transferência, sendo considerada apenas uma possibilidade. $\mathrm{Na}$ opinião do entrevistado, essa proposta pode ter surgido no intuito, inclusive, de padronizar a maneira como tem sido implementado esse tipo de política (de diferentes formas) nos municípios. Em relação a essa última discussão, foi mencionada a lei estadual que tem sido discutida na Assembleia Legislativa do Estado do Rio de Janeiro (ALERJ) - com a finalidade de contemplar o passe livre intermunicipal em nível estadual. Se aprovada, os recursos para cobrir as despesas com o transporte universitário seriam extraídos de verbas estaduais. Em termos políticos, isso seria um alívio não apenas para o atual governo, como para seu sucessor.

A última questão trabalhada na entrevista diz respeito ao acesso e ao conteúdo da lei vigente sobre o programa Passe Livre Universitário. As informações prestadas são de que é possível ter acesso sobre às
A QUALIDADE DE ENSINO QUE VOGE JÁ CONHECE.
INSCREVA-SE

AGORA!

口 PRESENCIAL

口 SEMIPRESENCIAL

口 EAD

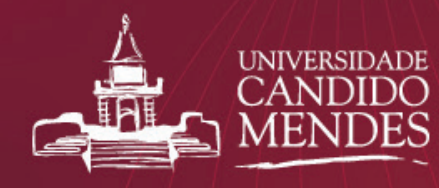

www.ucam-campos.br

22 2726-2400 
informações sobre a Lei $n^{0}$ 932, de 26 de fevereiro de 2013 - concessões de transporte intermunicipal a estudantes de curso superior e de nível técnico -, na própria Secretaria Educação, porém os entrevistados não souberam responder se a população possui outra forma de acessar o conteúdo, visto que, ao menos no período da pesquisa, a lei não foi encontrada on-line.

\section{Considerações finais}

A implementação dessa política de acesso ao ensino superior tem sido uma prática observada em várias prefeituras localizadas no Norte e Noroeste Fluminense, visto que poucos desses municípios possuem instituições de ensino superior, possibilitando, portanto, que a população consiga esse acesso por meio dos transportes universitários. No município de Itaocara, objeto de estudo deste trabalho, o programa tem sido oferecido desde 2013, tendo sofrido algumas pequenas alterações na oferta e referentes a alguns trâmites burocráticos, porém, a maioria de suas características originais - como seus critérios de elegibilidade e fonte de financiamento - permanecem as mesmas.

A prioridade dos gestores e atores envolvidos nesse processo está em proporcionar a oferta dos transportes universitários sem a intenção de alinhar a outros propósitos locais, como o de conciliá-la ao desenvolvimento econômico regional - como proposto pelo método da Tríplice Hélice - permanecendo, portanto, com seus objetivos iniciais, embora também proporcione outros resultados locais (não pretendidos intencionalmente). Em princípio, os gestores não possuem planos de estimar quantitativos sobre a demanda de procura de cursos, e também não é de interesse deles traçar o perfil dos futuros profissionais junto ao perfil econômico do município com intuito de inseri-los no mercado de trabalho local. Assim como também não tem sido interesse das empresas locais procurar por esses futuros profissionais da localidade. A ausência dessetipo de estratégia econômica dos setores público e privados dificulta relacionar modelos como a Tríplice Hélice como facilitador de desenvolvimento regional. Portanto, no momento, o governo local possui interesse apenas em cumprir seu papel de estado e suas responsabilidades constitucionais, provendo "benefícios" para a população, quando possível, sem assumir compromissos diretos com o desenvolvimento econômico e social.

Acredita-se também que os impactos gerados (sob os econômicos e sociais) são mais perceptíveis e eficazes sobre os indivíduos (e sua família) que fizeram ou ainda fazem uso do programa do que para a sociedade de forma generalizada, ao menos em um primeiro momento. Para que esse prognóstico seja confirmado e otimizado, a pesquisa prosseguirá e futuramente serão obtidos dados mais concretos e relevantes sobre o assunto.

\section{A QUALIDADE DE ENSINO QUE VOCE JÁ CONHECE.}

INSCREVA-SE AGORA!

口 PRESENCIAL

口 SEMIPRESENCIAL

口 EAD

www.ucam-campos.br

22 2726-2400 
Referências

ALMEIDA, Márlon Luiz de; SILVA, José Luís Gomes da; OLIVEIRA, Edson Aparecida de Araujo Querido. A inovação como fator de desenvolvimento regional. Revista Brasileira de Gestão e Desenvolvimento Regional, Taubaté, v. 3, n. 10, p. 314-350, set. 2014. Disponível em: http://www. rbgdr.net/revista/index.php/rbgdr/article/view/1483/406. Acesso em: 19 nov. 2018.

BRASIL. [Constituição (1988)]. Constituição da República Federativa do Brasil: promulgada em 5 de outubro de 1988. 4. ed. São Paulo: Saraiva, 1990.

CARVALHO, Márcia Marques de; WALTENBERG, Fábio D. Desigualdade de oportunidades no acesso ao ensino superior no brasil: uma comparação entre 2003 e 2013. Economia Aplicada, Ribeirão Preto, v. 19, n. 2, p. 369-396, June 2015 . Disponível em: http://www.scielo.br/scielo. php?pid=S1413-80502015000200369\&script=sci_abstract\&tlng=pt. Acesso em: 23 out. 2018.

CEDERJ. Fundação CECIERJ. Cursos x Polos 2018. Disponível em: < https://www.cecierj.edu.br/consorcio-cederj/cursos-x-polos/>. Acesso em: 20. nov. 2018.

DRAIBE, Sônia. Estados de Bem-Estar Social e estratégias de desenvolvimento na América Latina. Um novo desenvolvimentismo em gestação? Sociologias, Porto Alegre, ano 13, n. 27, p. 220-254, mai./ago. 2011, p. 220-254. Disponível em: http://www.scielo.br/pdf/soc/v13n27/ a09v13n27.pdf. Acesso em 30 out. 2018.

ETZKOWITZ, Henry; ZHOU, Chunyan. Hélice Tríplice: inovação e empreendedorismo-universidade-governo. Estudos Avançados, São Paulo, v. 31, n. 90, p. 23-48, maio 2017. Disponível em: http://www.scielo.br/scielo.php?script=sci_arttext\&pid=S0103=40142017000200023-\&lng=en\&nrmiso. Acesso em: 23 out. 2018.

IBGE - Instituto Brasileiro de Geografia e Estatística. Resultado dos Dados Preliminares do Censo - 2010. IBGE Cidades, Itaocara - RJ. Disponível em: https://cidades.ibge.gov.br/brasil/rj/itaocara/panorama. Acesso em: 06 set. 2019.

JACCOUD, Luciana. Proteção social no Brasil: debates e desafios. In: Ministério do Desenvolvimento Social. Concepção e gestão da proteção social não contributiva no Brasil. Brasília: Ministério do Desenvolvimento Social, 2009. Disponível em: http://unesdoc.unesco.org/images/0018/001830/183075por.pdf. Acesso em: 30 out. 2018.

KLIKSBERG, Bernardo. Ideias e experiências de capacitação gerencial. 0 desafio da exclusão: para uma gestão social eficiente. São Paulo: FUNDAP, 1997. p. 165-190.

PROCÓPIO, Igor Vieira; BASTOS, Suzana Quinet de Andrade Bastos; FREGUGLIA, Ricardo da Silva. Efeitos da Mobilidade Intermunicipal sobre a desigualdade de renda no Brasil: uma análise contrafactual. Pesquisa e Planejamento Econômico, Rio de Janeiro, v. 44, n. 3, p. 609-634, dez. 2014.

SANTOS, Vanessa Cristina dos; LEMOS José de Jesus Sousa. Mapeamento da pobreza no Estado do Rio de Janeiro: um estudo através de análise multivariada. In: XLII Congresso Brasileiro de Economia e Sociologia Rural (SOBER), Cuiabá; 2004. Anais. Disponível em: http://sober. org.br/palestra/12/110481.pdf. Acesso em: 06 set. 2019. 